\title{
Lexical concepts, cognitive models and meaning-construction
}

VYVYAN EVANS

\section{Abstract}

In this paper I address the role of words in meaning-construction. My starting point is the observation that the 'meanings' associated with words are protean in nature. That is, the semantic values associated with words are flexible, open-ended and highly dependent on the utterance context in which they are embedded. In attempting to provide an account of meaningconstruction that coheres with this observation I develop a cognitivelyrealistic theory of lexical representation and a programmatic theory of lexical concept integration. My fundamental claim is that there is a basic distinction between lexical concepts, and meaning. While lexical concepts constitute the semantic units conventionally associated with linguistic forms, and form an integral part of a language user's individual mental grammar, meaning is a property of situated usage-events, rather than words. That is, meaning is not a function of language per se, but arises from language use. I present an account of lexical concepts and the conceptual knowledge structures, cognitive models, with respect to which they are relativised. I also situate this theory within a usage-based account. I then develop a theory of lexical concept integration which serves to provide an account of how lexical concepts are combined in service of situated meaning-construction. As the constructs lexical concept and cognitive model are central to the theory of lexical representation and meaningconstruction I present, I refer to the approach developed here as the Theory of Lexical Concepts and Cognitive Models, or LCCM Theory.

Keywords: lexical concept; cognitive model; meaning-construction; semantic composition; lexical representation; word-meaning; LCCM theory; encyclopaedic knowledge. 


\section{The protean nature of word 'meaning'}

The traditional view of meaning-construction is based on the assumption that words have sense-units, or 'meanings', which are typically conceived as static 'lexical entries' (Allwood 2003; Pustejovsky 1995; Tyler and Evans 2001). Lexical entries are thought of in many formal and computational approaches to linguistic semantics as being tagged with syntactic, morphological and semantic features. These lexical entries combine, together with the grammatical structure of the sentence, to produce sentence-meaning, known technically as a 'proposition'. The combinatorial property of language that facilitates the integration of word 'meanings' with syntactic structures producing sentence-meaning is referred to as the principle of compositionality.

However, words in use do not behave in the straightforward manner assumed by this received view (Clark 1983; Coulson 2000; Croft 2000; Evans and Green 2006; Sweetser 1999). That is, the 'meaning' associated with a word in any given utterance appears to be, in part, a function of the particular linguistic context in which it is embedded. Put another way, word 'meaning' is protean, its semantic contribution sensitive to and dependent on the context which it, in part, gives rise to (Croft 2000).

To illustrate consider the following 'meanings' of fast.

(1) a. That parked BMW is a fast car.

b. That car is travelling fast.

c. That doddery old man is a fast driver.

d. That's the fast lane (of the motorway).

In each of these examples the semantic contribution of fast, what I will later refer to as its informational characterisation, is somewhat different. In (1a) fast has to do with the potential for rapid locomotion. In (1b) it has to do with rapid locomotion. In (1c) it relates to 'caused' motion beyond an established norm: a speed limit. And in (1d) fast concerns a venue for rapid locomotion. Examples such as these show that the view of open class words, as possessing fixed meanings, is untenable on closer scrutiny. The precise semantic contribution of any word is a function of the utterance context in which it is embedded, and, moreover, the sorts of (conceptual) knowledge these lexical entities provide access to, as I shall argue in detail. In other words, words don't have 'meanings' in and of themselves. Rather meaning is a function of the utterance in which a word is embedded, and the complex processes of lexical concept integration, an issue which is developed below. 


\section{Towards a cognitive compositional semantics}

Key to providing an account of the protean nature of words, in so far as they contribute to meaning-construction, is to provide a descriptively adequate account of i) the sorts of knowledge that words provide access to and ii) an account of how words, and their knowledge structures, are integrated or 'composed'. In the literature on lexical representation and semantic compositionality, three sorts of approaches have been invoked by scholars who have attempted to provide accounts which recognise that word-meaning is protean in nature. These three sorts of approaches can be characterised as follows:

i) Fine-grained polysemy (e.g., Lakoff 1987): involves a vast number of distinct senses which attempt to exhaust the possibilities that actually occur in language;

ii) Abstract/underlying lexical conceptual paradigms (i.e., monosemy; e.g., Pustejovsky 1995): employs cognitive/linguistic 'devices' that operate on underlying conceptual entities in order to "generate" surface interpretations of words;

iii) Underlying lexical entries (semantics) together with specific principles/rules of interpretation (pragmatics) (e.g., Herskovits 1986).

There are two difficulties common to each of these approaches as they attempt to account for (situated) variation in word-meaning. First, each of the accounts assumes that word-meanings are relatively stable, circumscribed knowledge structures which can be (relatively) straightforwardly identified. That is, they assume that word-meanings are relatively rigid, discrete sense-units, qua mental entities. More recently, a number of scholars have suggested that in fact word-meaning is less a discrete body of circumscribed knowledge. Rather, words serve as points of access to larger-scale encyclopaedic knowledge structures, which are potentially vast in scope as argued in detail below. On this view, words provide access to what I will refer to as a semantic potential, with different sorts of knowledge being potentially activated.

The second difficulty associated with the three views mentioned above, notwithstanding their attempt to handle variation in word-meaning, is that they do not constitute usage-based accounts of word meaning. That is, they make no attempt to relate their theoretical claims to the nature of situated meaning, and thus how words are used in context in order to express local communicative intentions. What a word 'means', which is to say, which part of its encyclopaedic knowledge potential is activated will always be a function of how it is being used in any given context. This includes both the linguistic context (the surrounding words and 
grammatical constructions), and the extra-linguistic context, including the situated communicative intention of the language user. Thus, we require an account of the nature of the semantic potential that words provide access to, and an account of how this semantic potential is constrained by virtue of the way in which words are combined and their contexts of use (i.e., the cognitive operations that facilitate differential activation of a word's semantic potential). The purpose of this section is to sketch such an approach. The remainder of the paper will develop the details.

\subsection{The semantic potential of words}

Recent work in linguistics (e.g., Haiman 1980; Fillmore 1982, 1995; Langacker 1987), and cognitive psychology (e.g., Barsalou 1992a, b, 1999, 2003; Zwaan 2004) suggests that an encyclopaedic account of wordmeaning is required for a descriptively adequate account of lexical representation and psycholinguistic processing. For instance, both Langacker, and Fillmore make the point that word-meaning is always a consequence of a larger knowledge structure with respect to which a given word is relativised. Fillmore models such knowledge structures in terms of what he refers to as semantic frames. These are conceptual entities that are, in part, defined by virtue of the linguistically encoded concepts that make them up, and which a given word necessarily evokes. Langacker (1987) makes a similar point arguing that a word's scope of predication (informally, its 'meaning') involves a profile and a base, where the profile designates a conceptual substructure within a larger unit, namely the base. For instance, the lexical item hypotenuse designates a substructure, the longest side, within a larger unit, namely a right-angled triangle. Thus, the 'meaning' of hypotenuse involves both the entity designated and the larger unit with respect to which the designated entity, the profile, is a substructure.

In addition to background knowledge structures of these kinds, words provide 'points of access' (in Langacker's terms) to large-scale encyclopaedic knowledge networks. Langacker models such knowledge structures in terms of domains, with domains being organised in hierarchical fashion forming a domain matrix (see Langacker 1987; see also Croft 1993; Evans and Green 2006: Ch. 7). A similar idea is developed in the work of Cruse (e.g., 2002; Croft and Cruse 2004) who refers to the encyclopaedic knowledge that words provide access to as purport.

There are two recent representative models of encyclopaedic semantics which attempt to account for how the semantic purport that a word provides potential access to is constrained. Both models take account of the utterance context (described in more detail below) which serves to 
constrain that part of a word's semantic potential which is activated. To illustrate the ideas just touched upon, I briefly present these models here.

The first is a language processing model developed by Zwaan (2004). Zwaan's model, which he refers to as the Immersed Experiencer framework, is concerned with modelling how language provides access to perceptual simulations (i.e., mental sensory rehearsals based on stored perceptual representations), which are integrated in service of language understanding. For instance, the lexical item red designates different things depending on the sorts of entities and experiences it relates to. Zwaan makes the point in the examples in (2), which are indicative of those he uses:

(2) a. The teacher scrawled in red ink all over the assignment.

b. The red squirrel is in danger of becoming extinct in the British isles.

red designates two different sorts of sensory experience precisely because the context constrains the sort of perceptual simulations we derive. That is, while the hue associated with the use of red in (2a) is quite a vivid red, the hue of the simulation prompted for by (2b) is likely to be closer to a dun/browny colour. In present terms, red has a large semantic potential, which relates to a range of different possible hues (one dimension along which the colour spectrum varies). That aspect of the word's potential which is activated is a consequence, in part, of the way it is constrained by the utterance context, and specifically the scene evoked by the utterance context.

A further important lesson from the work of Zwaan, and indeed others who take a perceptual simulation approach to language understanding (e.g., Bergen and Chang 2005), is that the semantic potential associated with words is perhaps largely non-linguistic in nature. That is, the semantic potential of red is not 'there' in the word itself. That is, whatever red designates, we are not dealing with purely linguistic knowledge. Rather, the form red provides access to perceptual information and knowledge, which can be reconstructed or simulated.

The second recent model I briefly discuss here is the proposal put forward by Allwood (2003). Allwood provides an account of what he refers to as meaning potential (see also Zlatev's 1997, 2003 related notion of use potential). Allwood explicitly argues that a word's meaning potential is

all the information that the word has been used to convey either by a single individual, or on the social level, by the language community. A consequence of this approach is that no attempt is made to distinguish between lexical and encyclopedic information in terms of the kind of information that is contained in 
the meaning potential. Meaning potentials contain both kinds of informationinformation deriving from use of language and information deriving from other experience with the world. (Allwood 2003: 43)

Central to Allwood's proposal is the position that a word's meaning potential is 'activated' providing a situated interpretation. Thus, meaning is always contextually determined, and is selected for from among the knowledge 'potential' that a word provides access to. To illustrate, consider the following examples adapted from Allwood (2003: 45):

(3) a. A carburettor is a part of a car.

b. A car need not have a carburettor since petrol can be directly injected.

Allwood makes the point that the use of carburettor in (3a) probably activates less detailed information than the use in (3b). Moreover, precisely what is activated is subject to individual language users, as different individuals will have different encyclopaedic knowledge structures, and thus different meaning potentials which can be both accessed and activated.

One of the purposes of the present paper is to provide an account of the sorts of cognitive and linguistic operations which must be in place in order for activation of a word's semantic potential to occur. However, the account of word-meaning I present in this paper differs in two important respects from the view presented by Allwood. First, I prefer the term 'semantic potential' to Allwood's notion of 'meaning potential'. This follows, as I shall argue in the next section, as words don't in fact have meanings. I argue that meaning is not a property of language per se, but rather is a function of language use, and thus, a characteristic of a process of meaning-construction, rather than relating to mental entities/units stored in memory. Meaning-construction is not an unpacking of stored information, as assumed in more traditional accounts. Rather, it is a constructive process, in which integration of lexical units involves differential access to the conceptual knowledge which lexical entities potentially afford access.

Second, I also argue for a distinction between purely linguistic knowledge, and the encyclopaedic knowledge (the semantic potential) that words provide access to (Allwood appears to assume that there is no principled distinction between lexical and encyclopaedic knowledge, a position that is hard to maintain). This I model in terms of the distinction between lexical concepts, stored linguistic knowledge units, and cognitive models, conceptual knowledge structures which constitute the semantic potential that lexical concepts provide access to. I use the term cognitive model profile to refer to a word's semantic potential. That part of the 
word's cognitive model profile that is activated in a given usage context I refer to as its informational characterisation - to be described in detail below).

\subsection{Meaning and use}

Having introduced the idea that a word relates to a semantic potential, I now discuss the relationship between language use and meaning. I do so by adopting a version of the usage-based thesis employed in cognitive linguistics (see Evans and Green 2006 for discussion).

Language use is integral to our knowledge of language, our 'language system' or 'mental grammar'. The organisation of our language system is intimately related to, and derives directly from, how language is actually used (Croft 2000; Langacker 2000; Tomasello 2003). Through processes of abstraction and schematisation (Langacker 2000), based on patternrecognition and intention-reading abilities (Tomasello 1999, 2003), language users derive linguistic units. These are relatively well-entrenched mental routines consisting of conventional pairings of form and meaning (Langacker 1987; see Evans and Green 2006: Ch. 4, for a review).

However, the range of linguistic units available to the language user massively underdetermine the range of situations, events, states, relationships and other interpersonal functions that the language user may potentially seek to use language to express and fulfil. One reason for this is that language users live in a socio-physical 'matrix' that is continually shifting and evolving. No two situations, feelings or relationships, at any given point in time, are exactly alike. We are continually using language to express unique meanings, about unique states of affairs and relationships, in unique ways. While language has a range of 'ready made' schemas, or linguistic units which can be combined to express a representative range of scenarios we may wish to refer to and describe, these necessarily underdetermine the mutability of human experience. As Langacker puts it, "linguistic convention cannot provide a fixed, unitary expression for every conceivable situation that a speaker might wish to describe." (Langacker 1987: 278). Accordingly, the linguistic units employed by language users can only ever partially sanction (in Langacker's e.g., 2000 terms) the situated way in which they are used. As Croft argues, language use involves solving a co-ordination problem, in which language users must employ non-conventional co-ordination strategies and devices. That is, language users typically employ the conventional repertoire of linguistic units, including patterns of assembling linguistic units (such as word order conventions, which are themselves linguistic units), in nonconventional ways. ${ }^{1}$ 
On this view, meaning, which is associated with the utterance (or usage-event), is a consequence of combining the conventional schemas or linguistic units in novels ways in order to solve the particular coordination problem at hand, thereby facilitating communication. The reason, then, for the apparently protean nature of the 'meanings' associated with words is that linguistic units are only ever realised as part of linguistic utterances, which are necessarily (i.e., by definition) situated, and thus part of an act of communication. But in being so realised, they have necessarily undergone context-induced 'shifts' in their semantic value, and so are never exactly the same as the lexical representations that sanction them.

Those scholars, however, who adhere to some form of Fregean compositionality are assuming, incorrectly, that the conventional semantic representations associated with linguistic units such as words are realised in language (use). They are not. As with the distinction between allophones and phonemes in phonological theory, linguistic representations, by analogy akin to phonemes, are never actually perceived, but are inferred based on how 'sense-shifted' words appear to behave in (situated) usageevents, as judged over many instances of use. In this, then, the job of the lexical semanticist is to employ meaning in usage-data, by analogy akin to allophones, in order to infer the existence of the underlying lexical concepts (stored mental schemas), akin to phonemes, which partially sanction the semantic contributions which surface.

This said, we are now in a position to provide some basic distinctions. First of all we need to provide a definition of an utterance. This is less straightforward a task than one might assume. As I will define it, a usageevent or utterance has a unit-like status, in that it represents the expression of a coherent idea, making (at least partial) use of the conventions of the language (informally, the 'norms' of linguistic behaviour in a particular linguistic community). In other words, an utterance is a somewhat discrete entity. However, I use the expressions 'unit like' and 'somewhat discrete' because an utterance is not an absolutely discrete nor a precisely identifiable unit. This follows as utterances involve grammatical forms such as word order, semantic structures, speech sounds, patterns of intonation such as pitch contours, slight pauses, and accelerations and decelerations, and so forth. While these properties converge on discreteness and unity, they do not co-occur in fixed patterns, and therefore do not provide a set of criteria for collectively identifying an utterance. In this respect, utterances differ from the related notion of sentence.

A sentence, as defined in particular by formal linguists, is an abstract entity. In other words, it is an idealisation that has determinate properties, often stated in terms of grammatical structure. For example, one definition of (an English) sentence might consist of the formula: $\mathrm{S} \Rightarrow$ NP VP. 
The notion of a sentence, while based on prototypical patterns found in utterances, is not the same as an utterance. Utterances typically occur spontaneously, and often do not conform to the grammaticality requirements of a well-formed sentence, as understood in formal linguistic theory. For example, in terms of structure, an utterance may consist of a single word (Hi!), a phrase (No way!), an incomplete sentence (Did you put the ...?), or a sentence that contains 'errors' of pronunciation or grammar because the speaker is tired, distracted, or excited, and so on. While much of formal linguistics has been concerned with modelling the properties of language that enable us to produce grammatically wellformed sentences, utterances often exhibit graded grammaticality (see Langacker 1987; see also Evans and Green 2006). As this discussion reveals, while a sentence can be precisely and narrowly defined, an utterance cannot. While sentences represent the structure associated with a prototypical utterance, utterances represent specific and unique instances of language use. Once a sentence is given meaning, context and phonetic realisation, it becomes a (spoken) utterance. Although the theoretical construct of 'sentence' might suit the aesthetic tastes of linguists of certain persuasions, as I am concerned with an account of lexical representation and meaning-construction that reflects how language is used, it is ultimately the utterance, rather then the idealised notion of the sentence, which is most relevant for present purposes.

Having provided this (qualified) definition of an utterance, we are now in a position to distinguish meaning from lexical representation. My claim is that the essential distinction between lexical representation and meaning is that while meaning is a property of the utterance, lexical representations are the mental abstractions which we infer must be stored as part of the language user's knowledge of language, in order to produce the range of novel uses associated with situated instances of a particular word (or construction). The meaning associated with an utterance I will refer to as a conception. Thus, conceptions are a function of language use. Lexical representations, or rather more technically, lexical concepts, represent the semantic pole of linguistic units, and are the mentallyinstantiated abstractions which language users derive from conceptions and the specific semantic contribution perceived to be associated with particular forms.

\subsection{An architecture for meaning-construction}

The conclusions to emerge from this discussion suggest a number of requirements for a theory of lexical semantics and the role of words in meaning-construction. We require both an account of lexical 
representation and a theory of concept integration, which together should contribute to a descriptively adequate and psychologically realistic account of meaning-construction. We require a theory of lexical representation which provides a descriptively adequate account of the kind of linguistic knowledge that language users appear to possess. We also require an account which provides a means of understanding how lexical representations interface with conceptual knowledge, which is to say, their semantic potential. That is, we require a theory that takes an encyclopaedic perspective on linguistic meaning. We also require an account of how lexical representations, together with the informational characterisations derived from the semantic potential available combine in order to provide situated meanings. Finally, as meanings associated with words are a function of specific utterances, and thus a consequence of discrete usage-events, our theories of lexical representation and lexical concept integration must be thoroughly usage-based in nature. As the two aspects of the theory I present are complex, I present a summary of the architecture here. Each of the constructs introduced are argued for in detail in later sections.

2.3.1. LCCM theory As the theory I present in the remainder of the paper centrally invokes the theoretical constructs of the lexical concept and the cognitive model, I refer to the model as the Theory of Lexical Concepts and Cognitive Models, or LCCM theory for short.

LCCM theory consists of i) an account of lexical representation (lexical concepts and cognitive models) and ii) an account of meaningconstruction (composition) of lexical concepts in a way which activates, or, in my terms, provides an access route through the cognitive models accessed by a given lexical concept. This can serve to highlight particular facets and relations of a given cognitive model at the expense of other facets and relations. As noted, the fundamental assumption is that meaning (more technically a conception), is a property of an utterance (a situated instance of language use), which is formed, in part, by cognitive operations which apply to the lexical representations (lexical concepts and the cognitive model profiles to which lexical concepts provide access sites) deployed by language users. Thus, meaning arises by virtue of language users forming interpretations based on the lexical concepts employed, the way lexical concepts are combined, and the access routes through the cognitive model profiles accessed by given lexical concepts. Moreover, these interpretations are always guided by background knowledge and extralinguistic context.

2.3.2. Lexical representation Knowledge of language includes i) lexical concepts, and ii) cognitive models. Lexical concepts constitute 
linguistically encoded concepts - that is conceptual knowledge encoded in a form that can be externalised via language. Thus, lexical concepts constitute the semantic pole of symbolic assemblies of form and meaning (see Langacker 1987), and are conventionally associated with linguistic forms of all kinds including words (the focus in this paper), bound morphemes, idiomatic phrases and grammatical constructions. Accordingly, lexical concepts, by definition, concern purely linguistic knowledge, as discussed in some detail later. A second important part of the lexical representation is the notion of the cognitive model, which is a large-scale coherent body of non-linguistic knowledge which lexical concepts provide access sites to. The range of cognitive models which are accessed, either directly or indirectly by a lexical concept, I refer to as a cognitive model profile. Individual cognitive models consist of facets (attributes) and relations (structural invariants) which hold between facets.

\subsubsection{Lexical concept integration The meaning-construction process} takes place by virtue of lexical concept integration ('composition'). This process involves two component processes: i) lexical concept selection and ii) fusion. Lexical concept selection involves selecting the most appropriate lexical concepts associated with each form in an utterance, guided by utterance and extra-linguistic context. Fusion, the second compositional process consists of two further constituent processes which are held to occur in tandem: i) integration and ii) interpretation. Integration involves the construction of larger lexical entities, driven by linguistic knowledge (lexical concepts). These larger lexical units, which I term lexical conceptual units, are then interpreted. That is, the larger unit receives an informational characterisation, which is to say, those parts of the cognitive model profiles (semantic potential) associated with each lexical concept in the larger unit is interpreted in a way that is in keeping with the larger unit. Put another way, integration provides (linguistic) instructions which serve to determine how the various lexical concepts are collectively interpreted, and thus, the access route that each individual lexical concept affords through its cognitive model profile. The result is that any given word will provide a unique activation of part of its semantic potential on every occasion of use. This follows as every utterance, and thus the resulting conception, is unique.

Accordingly, this view of compositionality is radically different from the received Fregean view. While Fregean compositionality assumes that each usage of a word recruits stable, context-independent information, LCCM theory assumes that the semantic value associated with a word will vary slightly every time it is used. An overview of the architecture is presented in Figure 1. 


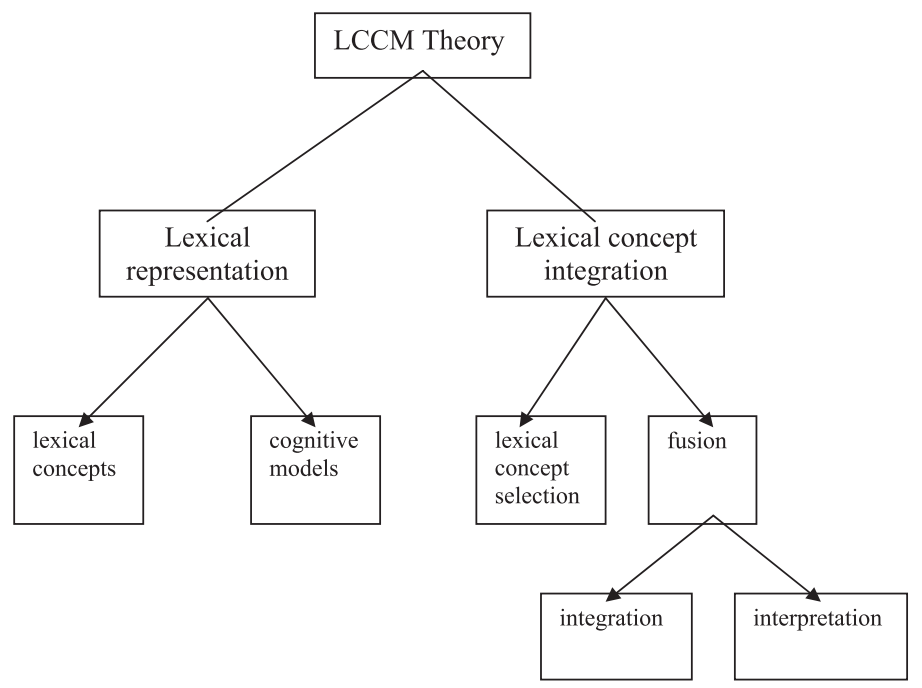

Figure 1. An overview of the architecture of LCCM Theory

\section{Lexical representation}

I now turn to a more detailed account of the first aspect of LCCM theory, namely how lexical representation is modelled. I defer a more detailed account of lexical concept integration until section 4 .

\subsection{Lexical concepts}

First, it is important to make clear that lexical concepts are not units of meaning. To reiterate a point central to the present argument, meaning (a conception) is a function of language use, and thus a property of an utterance. Lexical concepts are linguistically encoded concepts or mental representations that additionally serve as access sites to conceptual knowledge (cognitive model profiles). I now present six fundamental properties associated with the lexical concept qua mental entity.

3.1.1. Lexical concepts are form-specific First, lexical concepts are form-specific. That is, they are conventionally associated with specific linguistic forms. A corollary of this is that lexical concepts, the semantic pole of a form-meaning pairing, are necessarily language specific. Thus, each language consists of an inventory of language-specific lexical concepts.

3.1.2. Lexical concepts are associated with different sorts of forms Second, as lexical concepts are conventionally associated with a given 
linguistic form, it follows that lexical concepts are conventionally associated with a wide range of forms. The range of forms with which lexical concepts are conventionally associated includes overt forms: those which have resolved phonetic forms, such as cat, and implicit forms: those which have unresolved phonetic form, such as the ditransitive construction (subject verb obj1 obj2), e.g., John baked Mary a cake; John gave Mary the cake; John refused Mary the cake, etc. (see Goldberg 1995). Moreover, overt forms that have distinct lexical concepts conventionally associated with them include bound morphemes, 'simplex' words, 'complex' or polymorphemic words, and idiomatic expressions and phrases. In addition to grammatical constructions, implicit forms include grammatical 'relations' such as subject and object, and lexical classes such as noun and verb.

3.1.3. Forms are not lexical concept-specific Third, although lexical concepts are form-specific, a single form can be conventionally associated with a potentially large number of distinct lexical concepts which are related to degrees, as attested by the phenomenon of polysemy. ${ }^{2}$ That is, forms are not lexical concept-specific. A consequence of this is that the lexical concepts which share the same form can be modelled in terms of a semantic network (see Evans and Green 2006, for discussion). As any given lexical concept potentially provides access to other lexical representations it is associated with, I refer to the lexical concepts B, C, D ... in the same semantic network as lexical concept A as the semantic network profile of that particular lexical concept. Put another way, lexical concepts, which are linguistic entities, exhibit polysemy, and yet each lexical concept provides a distinct semantic potential.

3.1.4. Lexical concepts have a lexical profile Fourth, the definitional property of any given lexical concept is that it has a unique lexical profile, its unique 'biometric' identifier. A lexical profile is an extension of criteria presented in Evans (2004a), and akin to the notion of an ID tag (Atkins 1987) and behavioural profile (Gries 2006). While a lexical concept associated with a particular form possesses a particular semantic value-I will use the mnemonic of small capitals inside square brackets as a glossdetermining whether a particular usage of a form relates to one lexical concept rather than another is a matter of examining the selectional tendencies (i.e., semantic, collocational and formal patternings) associated with a given usage. While any given usage of a lexical concept will have its own unique selectional requirements, general patterns ('tendencies') can be established, and form part of the conventional knowledge associated with a particular lexical concept. ${ }^{3}$ General selectional patterns in 
terms of semantic, collocational and grammatical tendencies are what I refer to as a lexical profile.

Two sorts of information form a lexical concept's lexical profile. The first relates to semantic selectional tendencies. In Evans (2004a) this was referred to as the Concept Elaboration Criterion. The second relates to formal or grammatical selectional tendencies. In Evans (2004a) I referred to this as the Grammatical Criterion.

To get a sense of how the lexical profile can be used to identify distinct lexical concepts which underlie specific usage-events, I present the lexical profiles for a number of distinct lexical concepts encoded by the polysemous forms time (a noun) and fly (a verb). This discussion is based on Evans (2004a; see also Evans 2004b, 2005), and Evans and Green (2006). Nevertheless, I emphasise that the methodology I introduce here is primarily meant to serve as a guide for future research. Ultimately, establishing the existence of a given lexical concept is an empirical question, which can be investigated using psycholinguistic and corpus-based tools and methodologies (see e.g., Cuyckens et al. 1997; Gries 2006).

Consider the following examples illustrating examples sanctioned by distinct lexical concepts for time:

(4) Time flies when you're having fun.

(5) The time for a decision is getting closer.

(6) The old man's time [= death] is fast approaching.

(7) Time flows on (forever).

These instances of the lexical form time all appear in the 'subject' phrase. Moreover, the verb phrase which complements the subject phrase relates to a motion event. Thus, motion is being ascribed to the entities time contributes in prompting for, in each example. Yet, the semantic contribution associated with time appears to be distinct in each example. In the first example, the semantic contribution associated with time appears to relate to an assessment of temporal magnitude. Thus, we might gloss the semantic value associated with this instance of time as [DURATION]. In (5) the semantic contribution of time might be glossed as [MOMENT]. This follows as the conception associated with the utterance as a whole relates to a specific temporal moment when a particular decision is to be taken. Thus, the contribution of time in this example appears not to relate to a durational elapse, but rather a discrete instant. In (6) the semantic contribution associated with time appears to relate to an event, which extralinguistic context informs us is death. Thus, this instance might be glossed by [EVENT]. Finally, in (7), the semantic contribution associated with time appears to relate to an unending temporal elapse. In earlier work, I 
described this as the 'matrix' sense associated with time, in which we understand Time to be 'the' event in which all other events occur. Thus, the gloss we might apply to describe this instance of time is [MATRIX].

Based on the quite distinct semantic contributions associated with this range of usages of time, I argued in Evans (2004a) that there are a range of distinct lexical concepts associated with time identified by the glosses introduced above. Moreover, each of these distinct usages has a distinct lexical profile associated with it which supports this perspective. Let's illustrate for each.

I begin by examining the grammatical tendencies associated with each use of time. To do this, let's consider the kind of noun phrase in which each semantically-distinct use appears. We first note that the examples in (4) and (7) appear, on the face of it, to be similar. Neither is pre-modified by a determiner. However, further examples reveal that the [DURATION] lexical concept of time as in (4) can be determined by the definite article when the assessment of temporal magnitude is specific rather than generic, while the [MATRIX] lexical concept cannot be.

(8) During the dinner date, the time seemed to fly. [DURATION]

(9) *The time flows on (forever).

[MATRIX]

Indeed, this patterning appears consistent with the semantics of these uses. While the [MATRIX] lexical concept already relates to a unique referent, the event which subsumes all others, and thus further specification which the definite article would provide is superfluous, with assessments of temporal magnitude both specific and more generic readings are available, encoded by determiner patterns exhibited in (4) and (8) respectively. Thus, we can say that while both the [DURATION] and [MATRIX] lexical concepts appears to pattern formally like mass nouns (see Evans 2004a for evidence that they fail to allow determination by the indefinite article), the [DURATION] lexical concept, but not the [MATRIX] lexical concept, allows determination by the definite article.

The examples in (5) and (6) also exhibit unique patterns in terms of grammatical collocational tendencies, both from each other and from the examples in (4) and (7). The [MOMENT] lexical concept appears to pattern straightforwardly as a count noun, allowing determination by the definite article, as in (5), or by the indefinite article, as in (10).

(10) A time will come when we'll be forced to make a decision.

[MOMENT]

The [EVENT] lexical concept in (6) appears to require a pre-modifying genitive noun phrase followed by the enclitic possessive '-s', or else an attributive pronoun, serving a similar function. 
(11) His time $[=$ death $]$ is fast approaching.

Thus, in subject position, these uses of time all appear to have quite distinct formal selectional tendencies. Let's now turn to the semantic selectional tendencies associated with these uses of the lexical concepts associated with time. The point here is that the nature of the motion event encoded by the verb phrase is distinct for each of the semantic uses. Moreover, the choice of motion event type is compatible with the semantic value of the lexical concepts which underlie each use (see e.g., Evans 2004a, for detailed discussion). For instance, the [DURATION] lexical concept, and this particular variant - which in previous work I refer to as [TEMPORAL COMPRESSION] as this instance relates to an assessment of temporal magnitude which proceeds more 'quickly' than usual-is complemented by verb phrases which encode motion events which are rapid in nature, as evidenced by the example in (4). ${ }^{4}$ In contrast, the [MOMENT] lexical concept appears to allow a wider range of motion events, including imperceptible motion as in (12), rapid motion, as in (13), and terminal motion, as in (14).

(12) The time for a decision has gone/vanished/disappeared.

(13) The time for decision is racing towards us/fast approaching.

(14) The time for a decision is approaching/getting closer/has arrived.

The [EVENT] lexical concept appears to restrict the range of motion events which can collocate with it to terminal motion events, i.e., motion events which terminate 'at' the experiential locus, typically a human experiencer. Finally, the [MATRIX] lexical concept appears to require motion events which are non-terminal in nature. That is, it requires motion events which are on-going, a paradigm example being 'flow'. Thus, each of the examples represent specific instances of distinct lexical concepts which exhibit distinct semantic and formal selectional tendencies: distinct lexical profiles.

Now consider a further illustration of the lexical profile relating to distinct lexical concepts associated with a single form. This time we consider just a few of the many lexical concepts associated with a particular verb: (to) fly.

(15) The plane/bird is flying (in the sky).

(16) The pilot is flying the plane (in the sky).

(17) The child is flying the kite (in the breeze).

(18) The flag is flying (in the breeze).
[SELF-PROPELLED AERODYNAMIC MOTION]

[OPERATION OF ENTITY CAPABLE OF AERODYNAMIC MOTION]

[CONTROL OF LIGHTWEIGHT ENTITY]

[SUSPENSION OF LIGHTWEIGHT OBJECT] 
For convenience I have glossed the apparent semantic contribution of each of the instances of $f y$. The glosses appear in square brackets alongside the relevant examples. This data, and the glosses suggest that each instance is sanctioned by a distinct lexical concept associated with $f y$. If so, we should expect to be able to adduce a distinct lexical profile associated with each. Unlike nouns, for which a salient grammatical feature is how they are determined, a salient grammatical feature for verbs is transitivity. In terms of formal dependencies then, we see that the hallmark of the lexical concepts which license the uses in (15) and (18) is the lack of a direct object (an intransitive verb). This contrasts with the lexical concepts which sanction the examples in (16) and (17) which both require a direct object (a transitive verb). This distinction in transitivity fails to distinguish (15) from (18) and (16) from (17). For this we must rely on semantic tendencies. The hallmark of each of these lexical concepts is that they require distinct semantic arguments.

For instance, the [SELF-PROPELLED AERODYNAMIC MOTION] lexical concept which is held to sanction the use of $f y$ in (17) only applies to entities that are capable of self-propelled aerodynamic motion. Entities that are not self-propelled, such as tennis balls, cannot be used in this sense (*the tennis ball is flying in the sky).

The lexical concept which underlies the use of $f y$ in (16): [OPERATION OF ENTITY CAPABLE OF AERODYNAMIC MOTION], is restricted to the operation by an entity which can be construed as an agent, and moreover, to entities that can undergo self-propelled aerodynamic motion. Further, the entity must be able to accommodate the agent and thereby serve as a means of transport. This explains why planes and hot air balloons are compatible with this sense, but entities unable to accommodate an agent are not. This is illustrated by example (19).

??He flew the sparrow across the English Channel.

Nevertheless, entities which can be construed as being guided, or at least susceptible to being trained by a volitional agent which cannot accommodate an agent, are partially sanctioned by this lexical concept, as the following example illustrates.

(20) He flew the homing pigeon across the English channel.

In the case of [CONTROL OF LIGHTWEIGHT ENTITY] as evidenced by the use of $f y$ in (17), this lexical concept appears to be restricted to entities that are capable of becoming airborne by turbulence, and can be controlled by an agent on the ground. This lexical concept appears to be specialised for objects like kites and model/remote controlled aeroplanes. 
Nevetherless, particular instances of lexical items such as $f y$ appear to rely on what I refer to as multiple sanction. In the following example:

(21) The kite is flying (in the sky).

this use of $f y$ (ing) appears to be partly sanctioned by both the [SELFPROPELLED AERODYNAMIC MOTION] and the [CONTROL OF LIGHTWEIGHT ENTITY] lexical concepts. It adopts the grammatical patterning of the former lexical concept, but we understand that it must be controlled by an agent, rather then being self-propelled.

The final lexical concept, glossed as [SUSPENSION OF LIGHTWEIGHT OBJECT], selects for entities that can be supported by virtue of air turbulence, but remain 'connected to' the ground. This lexical concept applies to flags as well as hair and scarves, which can 'fly' in the wind.

3.1.5. Lexical concepts can be combined Fifth, lexical concepts can be combined in a range of ways, as determined by the nature of the lexical concepts involved (their semantic value as discussed below). This is the principle mechanism by which language functions in order to create flexible prompts for the process of interpretation (the informational characterisation derived by virtue of integrating lexical concepts in a way which provides differential activation of the semantic potential available via each individual lexical concept).

3.1.6. Lexical concepts possess a semantic value The final property associated with lexical concepts relates to the semantic value provided, in principle, by the lexical concept. While the lexical concepts mentioned thus far have been provided with semantic glosses, given in small capitals inside square brackets, these are simply shorthand labels for the complex conceptual knowledge structures that lexical concepts provide. Before considering the sort of linguistic and conceptual knowledge that lexical concepts provide or access, it is important to reiterate that although lexical concepts are conceptual in nature, they are knowledge structures which are specialised for symbolic representation (i.e., in language). Accordingly, they are of a quite different kind from the sorts of conceptual representations described by psychologists. In other words, while lexical concepts are conceptual in nature, they are not the same sort of entity that psychologists refer to as 'concepts'.

The semantic value associated with a lexical concept has (at least) five dimensions, treated in turn below. While the first relates to nonlinguistic knowledge, the remaining four are all unique to language, and thus constitute the linguistic knowledge associated with a given lexical concept. 


\subsubsection{Semantic potential First, lexical concepts possess a semantic} potential (in the sense discussed above). This semantic potential, via the process of interpretation (discussed in detail later), gives rise to an informational characterisation. This occurs by virtue of lexical concepts providing access to conceptual (or "encyclopaedic") knowledge structures. In LCCM theory these knowledge structures are characterised in terms of cognitive models, which collectively form a cognitive model profile for a given lexical concept. Cognitive models are described in detail later. Accordingly, lexical concepts provide access sites or, in Langacker's (1987) terms, "points of access" to conceptual knowledge. Indeed, it is this aspect of a lexical concept's semantic value which is often most important in accounting for the protean nature of word 'meanings' in language use.

However, the informational characterisation afforded by lexical concepts is not equally rich for all lexical concepts. For instance, there is a full distribution in terms of degree of specificity running from those lexical concepts which provide access to a highly detailed semantic potential to those which provide access which is highly impoverished. For example, even within a single lexical class, the lexical concepts [AUTOMOBILE] associated with the form car and [THING] associated with the form thing provide very different levels of detail in terms of their semantic potential. While [AUTOMOBILE] is richly detailed, which is to say the nature of the conceptual knowledge to which it provides access, [THING] is poorly detailed (or impoverished), in relative terms.

One obvious way in which levels of detail differ is in terms of the distinction between lexical concepts encoded by so-called open versus closed class forms. However, as Gentner and Boroditsky (2001) observe, this bifurcation is in fact better thought of in terms of a continuum. In present terms, this continuum in fact relates, in part, to differential level of detail in semantic potential.

3.1.6.2. Encapsulation The second dimension of the semantic value associated with a lexical concept relates to the notion of encapsulation. That is, lexical concepts serve to encapsulate often complex and informationally diffuse ideas. While it is the cognitive model(s) that the lexical concept provides access to which provides a coherent informational characterisation, a lexical concept nevertheless serves to encapsulate complex ideas by providing access at the relevant point in the knowledge 'matrix', i.e., the cognitive model profile. Evidence for this encapsulating function comes from culture-specific lexical concepts which cannot be easily captured in another language. An example from Korean is the lexical concept encoded by the form nunchi, which might be translated into English as 'eye-measure'. This lexical concept relates to the idea that one should 
be able to judge how others are feeling, such as whether a guest in one's home is hungry or not, and thus be in a position to offer food so that the guest is not embarrassed by having to request it. Lexical concepts serve to encapsulate complex ideas which are diffusely grounded in an intricate cultural web of ideas and information. They achieve this by providing access sites at particular 'points' in conceptual knowledge.

\subsubsection{Relational vs. non-relational The third dimension relates to} whether a lexical concept is relational or non-relational (Langacker 1987). For instance, while lexical concepts associated with forms labelled as 'nouns' are non-relational, lexical-concepts associated with forms which are labelled 'verb', 'adjective' or 'preposition', for instance, are relational. A consequence of this is that part of the semantic value associated with relational lexical concept includes information relating to the sorts of lexical concepts which the relational lexical concept can relate, i.e., 'argument structure' or 'valence'. For instance, the [CONTACT] lexical concept encoded by on encodes relational information relating to a figure and reference object ('ground'), as exemplified by the following prepositional phrase: the cat on the mat.

3.1.6.4. Temporal structure The fourth dimension concerns the temporal structure of a lexical concept. That is, some lexical concepts, i.e., those that are relational, encode how the temporal structure of the relation is being accessed, i.e., whether it evolves in time, as encoded by verbs, or whether it is provided as a 'gestalt', as encoded by prepositions. Langacker (1987) refers to this distinction as sequential scanning versus summary scanning.

3.1.6.5. Referentiality The final dimension relates to referentiality. Lexical concepts refer to or index entities of different sorts. Some lexical concepts provide denotational reference, referring to entities which are conceived as objectively existing, or at least as having some objective basis in the socio-physical world of experience, such as physical artefacts. Other lexical concepts provide deictic reference. They serve to refer to or index entities understood with respect to some deictic centre, such as the speaker's physical location or social status, etc. Other lexical concepts have anaphoric or cataphoric reference, referring to entities in the linguistic context itself. Indeed, while obvious examples of such lexical concepts include those encoded by, for instance pronouns, others include "shell" nouns (Schmid 2000), such as thing and aim, which take their reference from the propositions which they simultaneously serve to encapsulate and mark as coherent propositions. 
Table 1. Summary of properties of lexical concepts

\begin{tabular}{|c|c|}
\hline Property & Details \\
\hline lexical concepts are form-specific & $\begin{array}{l}\text { i.e., lexical concepts are conventionally associated with } \\
\text { a specific form. Thus, lexical concepts are necessarily } \\
\text { language specific. }\end{array}$ \\
\hline $\begin{array}{l}\text { lexical concepts are associated } \\
\text { with different sorts of forms }\end{array}$ & $\begin{array}{l}\text { i.e., lexical concepts constitute the semantic pole of } \\
\text { symbolic assemblies of form-meaning (linguistic units) } \\
\text { of all kinds }\end{array}$ \\
\hline $\begin{array}{l}\text { forms are not lexical concept- } \\
\text { specific }\end{array}$ & $\begin{array}{l}\text { i.e., are associated with a 'semantic network' of related } \\
\text { lexical concepts, and thus exhibit polysemy }\end{array}$ \\
\hline $\begin{array}{l}\text { lexical concepts have a lexical } \\
\text { profile }\end{array}$ & $\begin{array}{l}\text { i.e., a unique 'biometric' identifier associated with } \\
\text { formal and collocational tendencies }\end{array}$ \\
\hline lexical concepts can be combined & $\begin{array}{l}\text { i.e., lexical concepts can be combined in various } \\
\text { predictable ways, due to valence relations (relational } \\
\text { vs. non-relational lexical concepts and larger lexical } \\
\text { conceptual units), in service of activating semantic } \\
\text { potential and thus meaning-construction }\end{array}$ \\
\hline $\begin{array}{l}\text { lexical concepts possess a } \\
\text { semantic value: }\end{array}$ & $\begin{array}{l}\text { i.e., in context, lexical concepts provide an } \\
\text { informational characterisation. }\end{array}$ \\
\hline i) semantic potential & $\begin{array}{l}\text { i.e., access to a cognitive model profile (encyclopaedic } \\
\text { knowledge). }\end{array}$ \\
\hline ii) encapsulation & $\begin{array}{l}\text { i.e., provides access to the cognitive model profile at a } \\
\text { particular access site (in the cognitive model profile). }\end{array}$ \\
\hline iii) relational vs. non-relational & $\begin{array}{l}\text { i.e., relates to specific information concerning valence, } \\
\text { and thus combinatorial abilities and properties. }\end{array}$ \\
\hline iv) temporal structure & $\begin{array}{l}\text { i.e., encodes how the temporal structure of the relation } \\
\text { is being accessed, i.e., whether it evolves in time, as } \\
\text { encoded by verbs, or whether it is provided as a } \\
\text { 'gestalt', as encoded by, for instance, prepositions. }\end{array}$ \\
\hline v) referentiality & $\begin{array}{l}\text { i.e., lexical concepts refer to or index entities of differ- } \\
\text { ent sorts. Some lexical concepts refer to entities which } \\
\text { are conceived as objectively existing. Other lexical con- } \\
\text { cepts refer to entities understood with respect to some } \\
\text { deictic centre, such as the speaker's physical location. } \\
\text { Others refer to entities in the linguistic context itself. }\end{array}$ \\
\hline
\end{tabular}

A summary of the various properties associated with lexical concepts is provided in Table 1 .

\subsection{Cognitive models}

Having provided an overview of (at least some of) the key properties associated with lexical concepts, we now return to a key dimension associated with their semantic value. This concerns the semantic potential afforded by lexical concepts. This section is concerned with introducing and describing the construct of the cognitive model in more detail. 
My claim is that cognitive models, while related to the notion of frame (Barsalou 1999), semantic frame (Fillmore e.g., 1982; 1985; Fillmore and Atkins 1992) and domain (Langacker 1987), are distinct from all three. The distinct notion of cognitive model is necessary for understanding the way lexical concepts contribute to meaning-construction. The main claim is that lexical concepts provide sites of access to cognitive models and are relativised with respect to them.

In previous work (Evans 2004a, 2004b), I referred to the larger-scale knowledge structures with respect to which lexical concepts are relativised as cognitive models. The reason for preferring this term over the related notions of domain/base or semantic frame is that a cognitive model, in my sense, is a coherent, in large-part non-linguistic, knowledge structure, similar to what Langacker seems to have in mind, and in some statements to what Fillmore has in mind, particularly when he tends towards the view of a semantic frame as incorporating an (experiential) scene. That is, it is a richly specified conceptual entity, akin to what Barsalou (1999) refers to by his use of the term 'frame'. However, as with both Fillmore's notion of a semantic frame and Langacker's notion of a domain or a base, a cognitive model is accessed, at various points, by distinct lexical concepts, which are thus relativised to it, and in part, collectively constitute it. In other words, a cognitive model represents an interface between richlyspecified conceptual knowledge and nodes of access at particular points in the cognitive model provided by specific lexical concepts. Thus, lexical concepts provide particular established (i.e., conventional) perspectives or construals with respect to the set of cognitive models (cognitive model profile) accessed via a given lexical concept. Yet, a cognitive model is far richer than the sum of the lexical concepts which provide access sites to it. This follows as while lexical concepts are conceptual units specialised for symbolic representation in language, cognitive models are not. Rather, they are multi-modal conceptual entities, which can be used as a basis for perceptual simulations (see Barsalou 1999; and others, e.g., Prinz 2002 and Zwaan 2004).

Cognitive models relate to coherent bodies of knowledge of any kind. For instance, they include knowledge relating to specific entities, such as the complex knowledge associated with a specific entity such as 'car', or a more specific entity such as 'my car'. They include information such as whether the car needs filling up and when I last cleaned its interior. Cognitive models can relate to 'procedural' bodies of knowledge, such as 'cultural scripts' which form templates for how to interact in restaurants in order to be seated and secure a meal (cf. Sharifian's 2003 notion of cultural conceptualisations which are culturally 'distributed'). Cognitive models also include bodies of knowledge relating to more abstract entities 
such as containment, love and physics. They operate at varying levels of detail, and while stable, are dynamic being in a perpetual state of modification and renewal by virtue of on-going experience, mediated both by linguistic and non-linguistic interaction with others and one's environment.

Lexical concepts may be relativised with respect to more than one, typically many, cognitive models. As cognitive models are necessarily connected to and inherit structure from many others, a lexical concept can potentially be connected to a vast network of conceptual knowledge. Those cognitive models which are directly accessed by a lexical concept are referred to as primary cognitive models. The set of such primary cognitive models for a given lexical concepts is termed the primary cognitive model profile. The sorts of structured knowledge which is a subset of a given primary cognitive model I refer to as a secondary cognitive model. Such cognitive models relate to what I term a lexical concept's secondary cognitive model profile. This distinction is important to distinguish between literal and figurative language use (see Evans and Zinken to appear for detailed explication).

By way of illustrating the relationship between a lexical concept and its cognitive model profile, consider the lexical concept [FRANCE]. This lexical concept provides access to a large number of cognitive models (its cognitive model profile) at a particular access site, which is to say, a particular point in the cognitive model profile. Accordingly, it provides an encapsulating function. A very partial cognitive model profile for this lexical concept is provided in Figure 2.

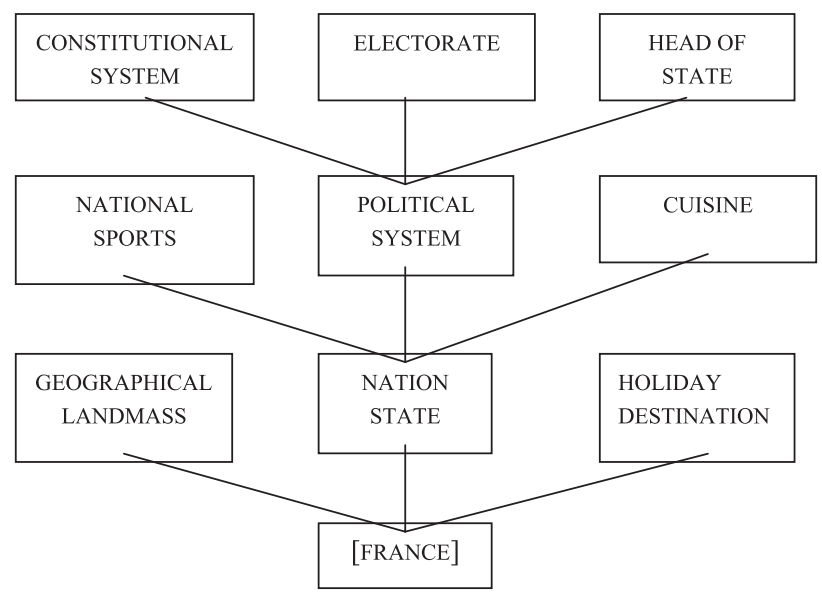

Figure 2. Partial cognitive model profile for [FRANCE] 
In Figure 2, the lexical concept [FRANCE] provides access to a potentially large number of knowledge structures. As each cognitive model consists of structured knowledge, providing access to other sorts of knowledge, we can distinguish between cognitive models which are directly accessed via the lexical concept, and those cognitive models which form substructures of the directly accessed (i.e., primary) cognitive models. That is, such secondary models are indirectly accessed via the lexical concept. Accordingly, a cognitive model profile is a structured inventory of knowledge (a semantic potential) which lexical concepts afford access to.

For instance, the primary cognitive model profile consists of (at the very least) the following cognitive models: GEOGRAPHICAL LANDMASS, NATION STATE and HOLIDAY DESTINATION. Each of these cognitive models provides access to a sophisticated and large body of knowledge. In Figure 2 a flavour of this is given by virtue of the various secondary cognitive models which are accessed via the NATION STATE cognitive model. These include NATIONAL SPORTS, POLITICAL SYSTEM and CUISINE. For instance, we may know that in France, the French engage in national sports of particular types, e.g., football, rugby, athletics and so on, and take part in competitions of various kinds including the FIFA football world cup, the six nations rugby competition and the rugby world cup, the Olympics, and so on. That is, we may have access to a large body of knowledge concerning the sorts of sports French people engage in. We may also have some knowledge of the funding structures and social and economic conditions and constraints that apply to these sports in France, France's international standing in these particular sports, and further knowledge about the sports themselves including the rules that govern their practice, and so on. This knowledge is derived from a large number of sources.

With respect to the secondary cognitive model of POLITICAL SYSTEM, Figure 2 illustrates a sample of further secondary cognitive models which are accessed via this cognitive model. In other words, each secondary cognitive model has further secondary cognitive models which it provides access to. For instance, (French) ELECTORATE is a cognitive model accessed via the cognitive model (French) POLITICAL SYSTEM. In turn the cognitive model (French) POLITICAL SYSTEM is accessed via the cognitive model NATION STATE. Accordingly, NATION STATE is a primary cognitive model while ELECTORATE and POLITICAL SYSTEM are secondary cognitive models.

Finally, it is worth reiterating that the cognitive model profile accessed via a lexical concept, while conceptual in nature, relates to knowledge that is non-linguistic. That is, it derives from our interaction with the world about us, including sense-perception. In contrast, lexical concepts are linguistic entities as described in the previous section, which also provide access to non-linguistic knowledge. In situated use, lexical concepts 
are always interpreted (a process described later), such that they provide an informational characterisation. This is achieved via activation of part of the semantic potential available.

\section{Lexical concept integration}

The discussion of lexical concepts and how they relate to cognitive models in the preceding section now allows us to examine how meaningconstruction occurs. That is, we are now in a position to see how lexical representations contribute to the formation of a conception. This process of meaning-construction I will refer to as composition. However, we are not dealing with Fregean compositionality. Rather, we are dealing with composition that makes use of lexical concepts, and the cognitive models with respect to which they are relativised.

Composition involves two processes, termed selection and fusion. Composition also accounts for semanticality - semantic well-formedness. I address each of these issues below.

\subsection{Lexical concept selection}

This is the process in which linguistic or extra-linguistic context selects for a particular lexical concept. Selecting the 'correct' lexical concept is required by fusion, the operation in which lexical concepts are integrated and the resulting integrations are interpreted. One of the complexities associated with meaning-construction, however, is that many processes occur at the same time, and thus, it is far from clear that the processes involved are, in psycholinguistic terms, sequential (Gibbs 1994).

An example of extra-linguistic context giving rise to selection follows.

(22) That recent hike is killing me.

The form hike has at least two lexical concepts associated with it. One relates to a long, typically cross-country walk, while another relates to an increase in financial charges or payments of some kind. In the context of a recent cross-country walk, the example in (22) might relate to sore body parts. In the context of, for instance, a recent central bank baserate increase, the speaker might be referring to the difficulty of keeping up with mortgage repayments. Thus, the extra-linguistic context provides a means of selecting the most appropriate lexical concept.

Now consider the following examples, which illustrate the role of linguistic context in selection.

(23) The judge asked the defendant to approach the bar.

(24) The customer ordered her beer at the bar. 
The form bar has a number of distinct lexical concepts associated with it, including the 'bar of a court' at which the judge sits, and a 'bar in a public house' at which alcohol is purchased and served. The appropriate lexical concept is selected in these examples due to the linguistic context.

Another example of linguistic context selecting the appropriate lexical concept is illustrated by ellipsis of the following kind, often termed zeugma.

(25) On the day my driving licence expired, so did my old dad.

In this example, a different lexical concept for expired is selected in each clause, despite the verb not appearing in the second clause. In the first clause, the lexical concept selected for can be glossed as [EXPIRATION OF PERMISSION], in the second [DEATH].

Despite being able to differentially identify the separate contributions of extra-linguistic and linguistic context with respect to lexical concept selection, the typical arrangement appears to involve a process I refer to as co-selection, involving both linguistic and extra-linguistic context. To illustrate, consider the following utterance adapted from a recent newspaper headline.

\section{(26) France shot down the EU constitution}

One of the points made by Croft (1993) in discussing a not dissimilar example, was that words often appear to take on 'meaning' only when it is clear what the 'meaning of the whole', what I refer to as the conception, relates to. That is, it is only by knowing what the entire utterance relates to that the 'parts' can be interpreted. For instance, France might relate to the geographical landmass, the political 'nation-state' entity, the government, the head of state, the people, a national sports team, a delegation from France, or something else. Similarly, shot down has a number of conventional interpretations associated with it, including the 'literal' meaning plus other conventional readings such as 'forcefully reject'. Similarly, EU constitution could relate to the membership of the EU, the health of the EU, or the new treaty and charter of rights and social provision recently presented to European Union member states for ratification.

However, co-selection relies upon selecting the most mutually appropriate readings associated with each of these expressions. That is, to understand the semantic contribution of one, we have to understand the semantic contribution of all. Thus, co-selection has to do with the interdependence of lexical concept selection. Selecting the most appropriate lexical concept associated with a given form is a mutually-involving 'symbiotic' process. 
Nevertheless, how is this co-selection process guided? I suggest that it proceeds by virtue of a discourse "anchor", which I refer to as the utterance topic. This is related to what Fauconnier (1997) terms the "base space'. The topic might be inferred based on the preceding discourse, the extra-linguistic context, or indeed, the utterance context itself. However, the topic constitutes a 'mini-theory' concerning the general nature of the conception, and is informed by the hearer's assumptions regarding the speaker's communicative intention. Thus, co-selection crucially relies on knowing the topic, which guides the co-selectional process. Indeed, this is what Croft was referring to when he talks of the whole leading to our understanding of the parts, what he describes in terms of the 'unity of the domain'. That is, unless we understand that the topic of the conception illustrated by (26) relates to European Union politics, we will be unable to make the most appropriate lexical concept co-selections, and thus be unable to build the conception that the newspaper headline writer has in mind.

Thus, co-selection can only proceed once we understand that the references that need to be assumed relate to a complex body of current affairs knowledge relating to the politics of the European Union. Indeed, to construct a conception similar to the one the headline writer presumably has in mind requires not only understanding the EU as a political and economic entity consisting of 25 European member states, it also requires knowledge relating to the raging debate that has held sway in many European countries about the direction of the $\mathrm{EU}$, and the recent ratification process relating to a new treaty, labelled 'EU constitution', which involved referenda being held in a number of European countries. The utterance in (26) relates to the rejection of the EU constitution by a majority of French voters in a recent referendum.

\subsection{Fusion}

Fusion concerns the process in which selected lexical concepts are composed such that they give rise to a particular conception. Fusion involves two component processes: integration and interpretation. I address each in turn.

4.2.1. Integration Integration is the process in which selected lexical concepts are incorporated into larger structures, what I refer to as composite lexical-conceptual structures. One way in which this process occurs is due to a process which Langacker refers to as elaboration. For instance, the conceptual representation associated with a verb such as kick encodes schematic roles for 'kicker' and 'kickee'. Indeed, this relates to the view 
that lexical concepts can be relational or non-relational as discussed earlier. These roles, what Langacker refers to as elaboration sites, can be integrated with, or, in Langacker's terms, elaborated, by lexical concepts encoded by other lexical forms, e.g., He kicked me.

Of course, integration can become more complex when it involves lexical concepts which have more than two elaboration sites. A case in point is the so-called ditransitive or double-object construction. Goldberg (1995) shows that this grammatical form has, in present terms, a conventional lexical concept associated with it which can be glossed as [X CAUSES Y TO RECEIVE Z]. The letters $\mathrm{X}, \mathrm{Y}$ and $\mathrm{Z}$ correspond to distinct elaboration sites (in Langacker's terms).

\section{(27) She kicked him the ball.}

Of course, there is more to integration than elaboration. Composite lexical structures can themselves be conjoined with other composite lexical structures. This process I refer to as constituency reanalysis. Essentially, this is the process in which composite lexical structures once established are treated as unitary entities or constituents at the next level of processing. For instance, the lexical concept encoded by and is specialised for integrating composite lexical structures. Thus, integration involves elaboration (building of composite constituents), and constituency reanalysis (building utterances from smaller 'meaning' constituents). However, and crucially, it is important to emphasise that what licenses these processes, providing coherence to the integration, is compatibility of the lexical concepts involved (rather than, for instance, semantically 'blind' syntactic processes, as in many formal approaches). Indeed, semantic incompatibility relates to utterances which are semantically anomalous, an issue discussed later.

4.2.2. Interpretation Interpretation is a process that proceeds in conjunction with integration. While integration serves to conjoin lexical concepts giving rise to composite lexical conceptual structures, interpretation serves to activate part of the semantic potential (cognitive model profile) that each lexical concept provides access to. It does so in a way that is consistent with the other lexical concepts of the composite lexical conceptual structure. In other words, it is not enough for meaning-construction to select an appropriate lexical concept, and integrate lexical concepts into a composite lexical-conceptual structure. In addition, the selected lexical concept(s) must then be interpreted within the composite lexicalconceptual structure, the new linguistic context, in which it occurs. This process of interpretation, then, provides the crucial break between lexical representation and meaning-construction. It is as a consequence of 
interpretation that a conception arises. In this section I will focus on interpretation as it applies to lexical concepts encoded by word classes of the following kind: nouns, adjectives, and verbs.

Throughout the paper I have referred to a construct termed access. This concerns the ability that lexical concepts have to interface with nonlinguistic knowledge, that is, the cognitive model profile. Thus each lexical concept has a unique cognitive model profile to which it affords access, by virtue of serving as an access site to non-linguistic knowledge at a unique, and thus different, point in the human knowledge matrix.

However, language use, and the consequent construction of a conception involve interpretation, and thus activation of just part of the cognitive model profile accessed via a lexical concept. This occurs by virtue of an access route through the cognitive model profile being established. This activation process is a consequence of situated language use, which I describe below. In addition to the establishment of an access route, there is a further kind of activation which I refer to as highlighting. While the establishment of an access route involves activation of a (typically limited) number of cognitive models in the cognitive model profile, highlighting involves activation of a distinct facet or facets within a single cognitive model. As highlighting is a consequence of situated access by a lexical concept, and thus, is prompted for by language, it can be further divided into two specific kinds, a function of the distinction between relational and non-relation lexical concepts described earlier. These two forms of highlighting I refer to as perspectivisation and adjustment, which I discuss in detail below. Figure 3 captures the distinct sorts of activation of a lexical concept's semantic potential that access affords.

\subsubsection{Cognitive model profiles In order to see how an access route is} established, I first briefly elaborate on the earlier discussion of a cognitive model profile. In order to do so, consider the lexical concept [воOK] as encoded by the form (a) book, and a very partial cognitive model profile that it affords access to (Figure 4).

The partial cognitive model profile in Figure 4 provides a diagrammatic representation of part of the semantic potential which the lexical concept [вОок] provides an access site to. That is, knowledge accessed by [BОOK] includes, at the very least, that a book is a physical entity, and is interacted with via a process of reading. These two distinct sorts of knowledge, knowledge relating to an artefact, and the process of reading are captured in Figure 4 by the two cognitive models BOOK and READING respectively. The two cognitive models are related by virtue of a READER who interacts with the physical artefact by reading the printed text. This relation holds between cognitive models (or facets), and is what 


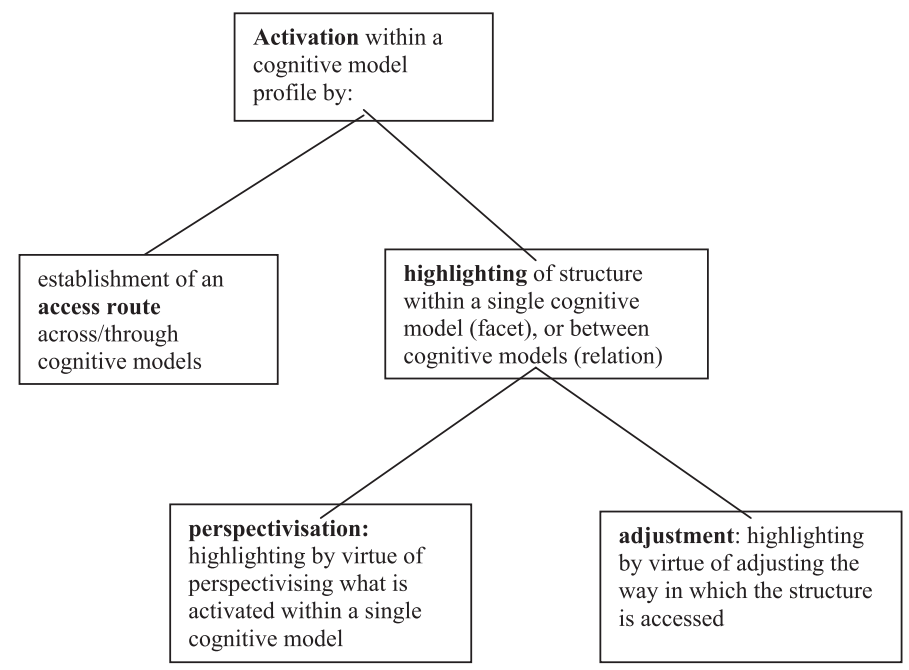

Figure 3. Activation processes within a cognitive model profile

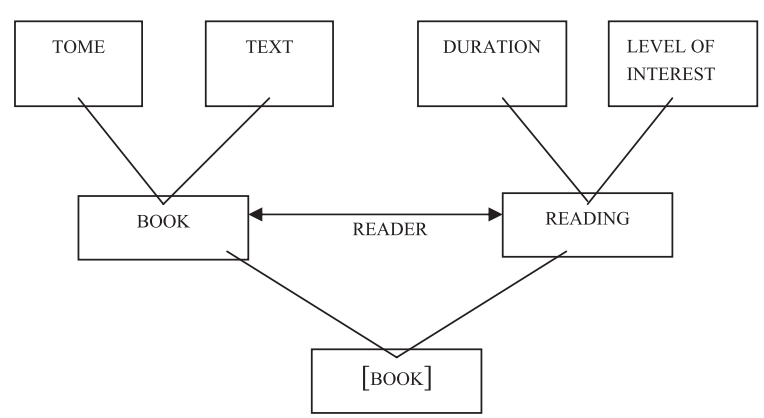

Level of facets

Level of cognitive models

Level of lexical concepts

Figure 4. The relationship between lexical concepts, cognitive models, and facets and relations

Barsalou (1992b) refers to as a structural invariant. I capture this relation in Figure 4 by a double-headed arrow, and the specific relation involved is signalled by the mnemonic reader. In addition, cognitive models consist of a large detailed, but structured, body of knowledge. The various attributes that make up this body of knowledge I refer to as facets. Figure 4 provides two facets for each of the cognitive models which [вОок] provides access to. The cognitive model BоOK relates to the physical artefact, consisting of, at the very least, knowledge as to the physical structure and organisation of a given book. This includes detailed knowledge 
concerning the material aspects of the artefact, including its dimensions, weight, binding (paper or cloth), and so forth. This facet of our knowledge about books I refer to as the tome facet. In addition to the physical organisation and construction of a book, books consist of text which is interacted with through the process of reading. his I refer to as the text facet.

The READING cognitive model relates to the process involved in interacting with books, especially the nature of the interaction with the text itself. One consequence of this interaction is that reading takes up a period of time, which I refer to as the DURATION facet. That is, depending on the amount of text involved, reading can take lesser or greater amounts of time. Another consequence of interaction with books is the level of interest that a given book holds for the reader. This I refer to as the LEVEL OF INTEREST facet. That is, while the reader might judge the book to be interesting another might be judged to be boring, and so on.

\subsubsection{The establishment of an access route Access routes are estab-} lished by virtue of situated language use. In order to see how, consider the following examples.

(28) That's a long book.

(29) That's a heavy book.

Each of these utterances involves a slightly different interpretation associated with the form book. That is, a consequence of each of these distinct utterances is that book achieves a distinct informational characterisation. This is achieved by virtue of each use of book being interpreted in a way consistent with the utterance context such that a slightly different access route is established through the cognitive model profile accessed via [воОк].

For instance, the conception that results from (28) has to do with an assessment of a relatively extended duration required in order to read the book in question. In contrast, the conception associated with (29) has to do with an assessment as to the weight associated with the book in question. The process of interpretation then involves differential activation of aspects of the semantic potential accessed via [воок], in a way that is consistent with the lexical concepts encoded by the other forms which make up the utterance context. Thus, the example in (28) involves an access route which serves to activate the READING cognitive model profile. In contrast, (29) involves an access route which involves the activation of the BOOK cognitive model.

Now let's consider a more complex example, involving an access route involving access in several cognitive models. To do so reconsider the 
partial cognitive model profile accessed via the lexical concept [FRANCE] in Figure 1. Now re-consider the utterance in (26), above, re-produced below:

\section{(26) France shot down the EU constitution}

In this example interpretation requires that an access route is established through the cognitive model profile accessed via [FRANCE] in a way that is consistent with the lexical concepts associated with the other linguistic forms and units in the utterance. The interpretation associated with France in this example is that we are concerned with the French electorate, and specifically that part of the French electorate which voted against ratification of the EU constitution. In other words, [FRANCE] in this example achieves an informational characterisation which is attained by activating the cognitive models which are shown in bold in Figure 5.

What this example shows is that an access route typically involves the activation of a number of distinct cognitive models, in order to facilitate a situated interpretation, i.e., the informational characterisation of a lexical concept.

It is also worth pointing out that this sort of example feels like a more figurative instance of language use than say an example involving [FRANCE] as in the following:

(30) France is a country of outstanding natural beauty.

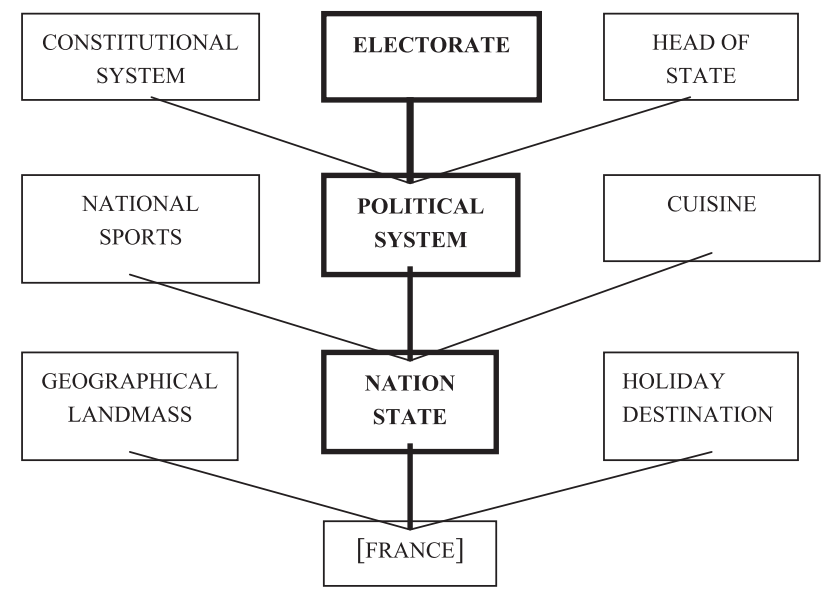

Figure 5. Access route established by the interpretation of [FRANCE] in the utterance France shot down the EU constitution 
The use of France in (30) constitutes an instance of what might be thought of as metonymy (see Evans and Zinken to appear for detailed discussion of how LCCM theory accounts for figurative language such as metonymy).

4.2.2.3. Highlighting As previously noted, in addition to the general activation process which involves the establishment of an access route across cognitive models, there is a further activation process. This I refer to as highlighting. This process involves activation within a single cognitive model. There are two variants of highlighting which I term perspectivisation and adjustment. The distinction between the two relates to a fundamental distinction between the kinds of lexical concepts encoded in language: those that are relational (as encoded by, for instance, verbs, adjectives and adverbs), and those that are non-relational (as encoded by noun forms). The basic insight is that while non-relational lexical concepts determine what is activated - the highlighting process of perspectivisation-relational lexical concepts can influence how the conceptual structure is activated - the highlighting process of adjustment.

4.2.2.3.1. Perspectivisation This is an interpretation process involving activation by virtue of lexical concepts which are non-relational in nature, and thus as encoded by noun forms. ${ }^{5}$ That is, lexical concepts of this kind activate structure within a single cognitive model, such as determining which facets are highlighted, (rather than determining how the facets are highlighted). To illustrate, consider the following examples.

(31) a. That's a heavy book to carry around in your school bag all day.

b. That antiquarian book is so old that it is illegible in places.

(32) a. That book is really long.

b. That book is really boring.

Reconsider the partial cognitive model profile accessed via the lexical concept [воОк] presented as Figure 4. The examples in (31) give rise to a conception which establishes an access route in the BOOK cognitive model. The difference between the informational characterisation associated with book in each of the examples in (31) relates to the two distinct facets TOME versus TEXT. That is, the process of interpretation that gives rise to the two distinct conceptions (or readings) associated with each utterance comes from utterance context informing which facet is highlighted. In (31a) the utterance context, particularly the lexical concept associated with heavy, serves to highlight the TOME facet, and especially those aspects of our 
knowledge relating to the physical properties associated with heavy books which mean that they are physically demanding to carry around over an extended period of time. In contrast, the informational characterisation associated with book in (31b) relates to the TEXT facet. This is highlighted due to our understanding that because of the ageing process, and wear, old books may have text which is illegible. Thus, the informational characterisation associated with [воок] is slightly distinct in each of these examples by virtue of the process of perspectivisation, which serves to perspectivise a distinct facet in each example.

The examples in (32) illustrate perspectivisation of distinct facets in the cognitive model of READING. The example in (32a) perspectivises the DURATION facet. This follows as the conception involves understanding [воок] as activating structure relating to the reading process, and in particular, an assessment that the book in question takes a relatively great period of time in order to be read. In contrast, the informational characterisation associated with [воОк] in (32b) results from perspectivising the LEVEL OF INTEREST facet. That is, the semantic value of [воOK] is slightly different in this example. As with the examples in (31), the examples in (32) reveal that the 'meaning' associated with book is a function of different 'paths' of activation, involving distinct access routes, and distinct sorts of activation within a single cognitive model.

4.2.2.3.2. Adjustment We now turn to the second of the two activation processes known as highlighting. This relates to relational lexical concepts, as encoded by adjectives, prepositions and verbs. This process of interpretation I refer to as adjustment. I do so in order to distinguish the process from that of perspectivisation. The reason for selecting a distinct term is that the process involved appears to be slightly different, a consequence of the relational nature of these lexical concepts. The main difference appears to be that while perspectivisation affects the nature of the knowledge structure(s) being highlighted (i.e., 'what', e.g., TOME vs. TEXT facet), adjustment affects the quality of, and thus 'how' the entity in question is being highlighted. Consider some examples by way of illustration.

a. a small mouse

b. a small elephant

(34) a. a red pen

b. a red squirrel

a. a good man

b. a good meal 
With the examples of small, and red in (33) and (34) the sensory qualities interpreted will depend on the lexical concept with respect to which it is fused. That is, the informational characterisation associated with small varies not in terms of the notion of relative size (what), but rather how we interpret this. Thus, we interpret the absolute dimensions that apply to small in (33a) to be quite distinct from those in (33b). Yet, there is no confusion that 'small' can apply equally to an elephant or a mouse, each of which (a small mouse versus a small elephant) are radically different in terms of their absolute dimensions.

Similarly, the interpretation of good is adjusted depending on the composite lexical-conceptual structure it is involved in. For instance, a good man might possess attributes such as physical beauty, honour, providing for his family, and so on, depending upon context. The sorts of qualities associated with a good meal, however, are more likely to include the size of the portions, how tasty the food is, that it consists of wholesome ingredients, and so on. Thus, we adjust how the knowledge associated with good is being activated rather than what is being activated, a consequence of the relational (here attributive) nature of the lexical concept associated with good.

Now consider the lexical concepts encoded by the verb bake: the wellknown change-of-state/creation 'alternation'.

(36) Fred baked the potato.

(37) Fred baked the cake.

In these examples the informational characterisation associated with bake is adjusted in the light of the informational characterisation accessed by virtue of the other lexical concepts integrated in the composite lexicalconceptual structure. Previous researchers have referred to this process of adjustment by terms such as 'accommodation' (e.g., Talmy 1977) or 'coercion' (e.g. Pustejovsky 1995; Goldberg 1995). However, such scholars have emphasised the role of other aspects of language in 'coercing' the 'meaning' of the verb. For instance, Goldberg argues that sentencelevel verbal argument constructions coerce verbal meanings. The reason for selecting the term adjustment here is that the process I am describing relates not primarily to 'one-sided' coercion by the grammatical construction. Rather, the adjustment is a consequence of a mutually interdependent process of interpretation in which bake provides access to an informational characterisation associated with rich conceptual knowledge, part of which is highlighted in conjunction with and in response to the informational characterisation provided by other lexical concepts in the composite lexical conceptual structure. Thus, in addition to a process of lexical concept integration, there are, additionally, activation processes: 
perspectivisation and adjustment, which are processes of interpretation. These necessitate accessing cognitive models which lexical concepts provide access sites to, but the nature of the information accessed must be 'calibrated' with respect to the contribution of the other lexical concepts in the composite lexical conceptual structure. Moreover, adjustment is also guided by other 'contextualisation cues' such as speaker communicative intention, extra-linguistic context, accompanying gestures (see Kendon 2004 for an overview) and so forth. In the light of the discussion in this section, Figure 6 presents an overview of the lexical concept integration process.

\subsection{Semanticality}

Finally, having provided a programmatic sketch of how the constructs of lexical concepts and cognitive models might relate to a cognitively realistic approach to compositional semantics, I now address the semantic 'well-formedness' of conceptions. Indeed, conceptions are, by definition, semantically coherent. We will see that this is the case by considering situations in which conceptions fail.

The term semanticality, introduced into linguistics by Pustejovsky (1995), relates to the semantic well-formedness of an utterance. Semantically well-formed utterances give rise to conceptions. Utterances that fail in this regard are semantically anomalous. However, as with the related notion of grammaticality, semanticality or semantic anomaly is a matter of degree rather than an either/or distinction.

The principle reason for semantic failure appears to be a failure in matching semantic selectional dependencies, discussed earlier. Of course, semantic selection tendencies, or collocational patterns, are a consequence of semantic compatibility. Even lexical concepts that are potentially dissonant and can be said to clash, need not result in failure to form a conception. This follows as the semantic potential which lexical concepts provide access sites to is vast and extremely richly detailed, allowing the possibility of novel access routes, perspectivisations and adjustments resulting in a semantically well-formed conceptions, particularly with appropriate extra-linguistic context to assist in the co-selection process. Indeed, this is the strategy that prevails in so-called 'figurative' language use (see Evans and Zinken to appear).

To consider this phenomenon consider some examples involving the verb began.

(38) a. He began the book

b. ?He began the dictionary

c. ??He began the rock 
While the first example evidences a semantically well-formed utterance, the second example is semantically odd. This follows as dictionaries are not something we 'begin', as their function relates to reference and lookup. Thus, there is a mismatch between the informational characterisations provided by the cognitive model profiles as accessed by the lexical concepts in this utterance.

However, in certain situations extra-linguistic context can help, as pointed out by Pustejovsky (1995). For instance, Malcolm X, the African American civil rights activist who promoted violent struggle, is famously known to have read a dictionary while in prison 'like a book'. As the only book available to him was a dictionary he began at the letter A and read through to Z. In such a situation, the example in (38b) becomes semantically acceptable.

The example in (38c) is semantically anomalous as a rock is not an entity that has internal structure that is subject to a sequential process that can be construed as having a starting point. Thus, while a dictionary is a book, that can, under certain novel contexts, be construed as an entity that can be read sequentially, (38b) is less semantically anomalous that (38c). ${ }^{6}$

Interestingly, notice that where another form has a somewhat related lexical concept as when two lexical concepts collocate: start the car, the lexical concept encoded by begin cannot be used: ?begin the car, unless by 'begin the car', we mean something like 'begin its construction'.

The point then, is that both the lexical profile associated with lexical concepts and the semantic value of lexical concepts, as defined, are necessary for understanding the phenomenon of semanticality and semantically anomalous composition.

\section{Conclusion}

In this paper I have made a number of proposals in order to develop a cognitively-realistic account of lexical semantics and meaningconstruction: the Theory of Lexical Concepts and Cognitive Models, and thus to develop an account which is consonant with the facts of language use. I argued that meaning is not a property of words, but rather of the utterance: that is, a function of situated use. Words, as such, don't have 'meanings'. The representational aspects of language that contribute to meaning involve two dimensions: lexical representations, including access to non-linguistic, conceptual knowledge, and a cognitively-realistic account of compositionality. I modelled lexical representation by developing the construct of the lexical concept, and the conceptual structures that lexical concepts provide access to. Lexical concepts are relatively 


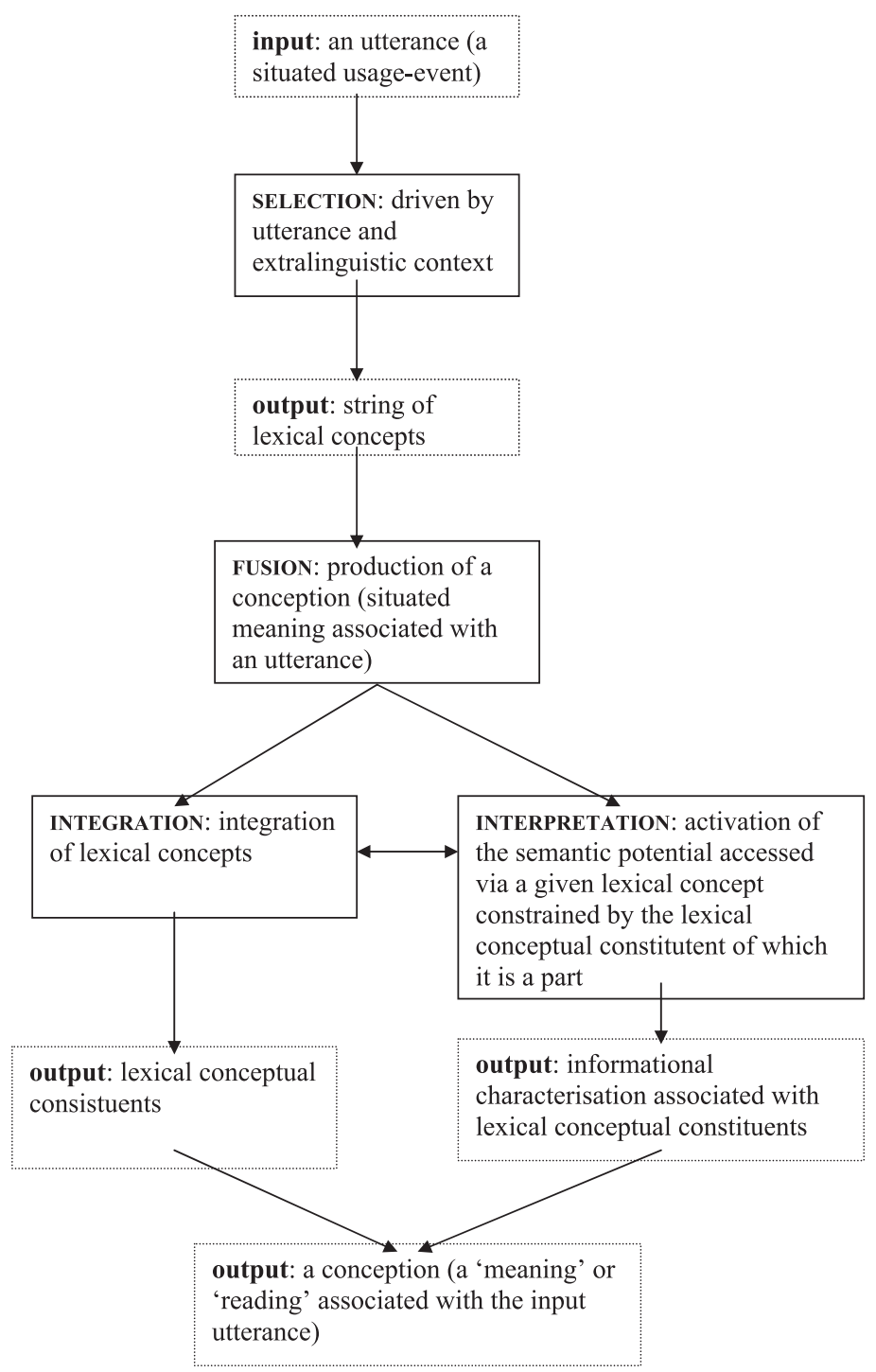

Figure 6. Meaning-construction in LCCM theory

schematic units of knowledge which are relativised to (and thus provide access to) conceptual knowledge at particular 'sites' in the knowledge system. Conceptual knowledge is organised into cognitive models which form an encyclopaedic knowledge network. Lexical concepts are integrated, 
guided by a number of principles, giving rise to utterance meaning: a conception.

The significance of LCCM theory developed here is that we are provided with a distinction between meaning and representation. Moreover, the present approach provides a way of connecting the concerns of lexical and compositional semantics with cognitive approaches to grammar (e.g., Goldberg 1995; Langacker 1987) and the conceptual processes which underpin these, as studied, for instance by Fauconnier and Turner (e.g., 2002). Current and future research aims to develop the approach, apply it to a wider array of data, and develop a lexically-based account of metaphor and metonymy (e.g., Evans and Zinken to appear). In particular, one important area that I have not addressed in any detail in this paper is the nature of the lexical profile associated with lexical concepts (although see Evans 2004a). In particular, future research aims to examine the formal (i.e., syntactic) reflexes of the semantic value of lexical concepts such as the constructs of relationality, temporal structure and referentiality (although see Goldberg 1995; and particularly Langacker 1987).

Communication employing language can succeed or fail because of the complex possibilities involved in meaning-construction. While I have attempted to sketch some of the linguistic processes involved, I have necessarily missed out the sorts of interpretative principles that relate to inferential processes as discussed in the 'pragmatic' tradition ranging from work by scholars such as Searle (e.g., 1969), to Grice (e.g., 1975), and particularly Sperber and Wilson (e.g., 1995). I have also not addressed the 'social' psychological perspective as represented in work on social roles, contexts, and settings ranging from that of Erving Goffman (e.g., 1981) to the role of speaker/hearer interaction, and common knowledge and context as developed in the work of Herbert Clark (e.g., 1996), or Chris Sinha (e.g., In print). I have also not addressed in any detail the contribution of closed-class structures such as grammatical constructions, as addressed in the Construction Grammar tradition (e.g. Goldberg 1995, 2006; Michaelis 2003). Nor have I addressed the role of contextualisation cues, including colloquial language use, and intonation, etc., as represented in the interactional sociolinguistics tradition associated with the work of John Gumperz (e.g., 1982), and the discourse-based work of scholars such as Deborah Schiffrin (e.g., 1987), and Wallace Chafe (e.g., 1994). A fuller account of meaning-construction must at least include all these things.

Finally, the research presented here is programmatic. Accordingly, it is fitting that I conclude with a caveat. A significant portion of the account of meaning-construction presented here rests on the construct 
of the cognitive model profile. As cognitive models are claimed to be psychological entities, we require a fully fleshed out psychologically-based account. Moreover, I have presented no experimental evidence for the different levels of constructs I have posited. Clearly, psycholinguistic evidence will be required in order to support the theory I have presented here.

Received 1 August 2005

University of Brighton, $U K$

Revision received 16 May 2006

\section{Notes}

* I gratefully acknowledge detailed comments on an earlier version of this paper by Alan Cienki, Malgorzata Fabiszak, Shane Lindsay, and two anonymous reviewers for Cognitive Linguistics. I am also indebted to the 2005-6 cohort of students on the MA in Cognitive Linguistics at the University of Sussex, who worked through many of the ideas presented here with me. Some of the proposals in this paper have also benefitted from discussions with Jörg Zinken. Many of the specific theoretical suggestions have been presented at a number of venues. These include the Department of Psychology seminar series, University of Portsmouth, May 2005; the International Cognitive Linguistics Conference held in Seoul, South Korea, July 2005; the New Insights in Semantics and Lexicography (NISL) conference, held in Lublin, Poland, September 2005; the New Directions in Cognitive Linguistics (NDCL) conference held at the University of Sussex, October 2005; and the MetNet workshops $1 \& 2$, funded by the ESRC, which were held at the Universities of Leeds and York in May 2006. I am grateful to members of the audiences at these venues for their feedback which has informed the version of LCCM theory presented here. Finally, I gratefully acknowledge the support and advice of Adele Goldberg. The author is affiliated to the University of Brighton. Author's E-mail address:〈vyv.evans@brighton.ac.uk〉.

1. As Croft (2000) notes, this is precisely why language change is possible, and proceeds as rapidly (in relative terms) as it does.

2. See Evans (2005) and Tyler and Evans $(2001,2003)$ for detailed discussion of polysemy.

3. Identifying such selectional tendencies is ultimately an empirical question. Important techniques in this regard have been developed recently in corpus linguistics. See for instance Gries (2006) and Stefanowitsch and Gries (2003).

4. The TEMPORAL COMPRESSION variant of DURATION associated with time can also be structured in terms of motion events which relate to a lack of perceptual awareness, such as the following: Where has the time gone? The time seemed to have vanished, etc.

5. Note that by non-relational I have in mind valence properties. Nouns are conceptually 'independent' in that they refer to conceptually autonomous entities. In Gentner and Borodsitsky's (2001) terms they are cognitively rather than linguistically oriented.

6. It has been pointed out to me by Shane Lindsay that the example in (38c) would not be anomalous in the context of a sculpture.

\section{References}

Allwood, Jens

2003 Meaning potentials and context: Some consequences for the analysis of variation in meaning. In H. Cuyckens, R. Dirven and J. Taylor (eds.). Cognitive 
Approaches to Lexical Semantics. Berlin/New York: Mouton de Gruyter, 29-66.

Atkins, Beryl T.

1987 Semantic ID tags: Corpus evidence for dictionary senses. Proceedings of the Third Annual Conference of the UW Centre for the New Oxford English Dictionary, 17-36.

Barsalou, Lawrence

1992a Cognitive Psychology: An Overview for Cognitive Scientists. Hillsdale, NJ: Lawrence Erlbaum.

1992b Frames, concepts and conceptual fields. In Adrienne Lehrer and Eva Kittay (eds.). Frames, Fields and Contrasts. Hillsdale, NJ: Lawrence Erlbaum, 21-74.

1999 Perceptual symbol systems. Behavioral and Brain Sciences 22, 577-609.

2003 Situated simulation in the human conceptual system. Language and Cognitive Processes 5(6), 513-562.

Bergen, B. K. and N. C. Chang

2005 Embodied construction grammar in simulation-based language understanding. In J.-O-Östman and M. Fried (eds.), Construction Grammars. Amster-

Chafe, Wallace dam: Benjamins, 147-190.

1994 Discourse, Consciousness and Time: The Flow and Displacement of Conscious Experience in Speaking and Writing. Chicago: Chicago University Press.

Clark, Herbert

1983 Making sense of nonce sense. In Levelt, W. J. M. and R. Jarvella (eds.), The

Process of Language Understanding. New York: Wiley, 297-331.

1996 Using Language. Cambridge: Cambridge University Press.

Coulson, Seana

2000 Semantic Leaps: Frame-shifting and Conceptual Blending in Meaning Construction. Cambridge: Cambridge University Press.

Croft, William

1993 The role of domains in the interpretation of metaphors and metonymies. Cognitive Linguistics 4, 335-370.

2000 Explaining Language Change: An Evolutionary Approach. London: Longman.

Croft, William and D. Alan Cruse

2004 Cognitive Linguistics. Cambridge: Cambridge University Press.

Cruse, D. Alan

2002 Aspects of the micro-structure of word meanings. In Ravin, Y. and C. Leacock (eds.), Polysemy: Theoretical and Computational Approaches. Oxford: Oxford University Press, 30-51.

Cuyckens, Hubert, Dominiek Sandra and Sally Rice

1997 Towards an empirical lexical semantics. In Birgit Smieja and Meike Tasch (eds.), Human Contact Through Language and Linguistics. Frankfurt: Peter

Evans, Vyvyan Lang, 35-54.

2004a The Structure of Time: Language, Meaning and Temporal Cognition. Amsterdam: John Benjamins.

2004b How we conceptualise time. Essays in Arts and Sciences 33(2), 13-44.

2005 The meaning of time: Polysemy, the lexicon and conceptual structure. Journal of Linguistics 41(1), 1-39. 
Evans, Vyvyan and Melanie Green

2006 Cognitive Linguistics: An Introduction. Edinburgh: Edinburgh University Press.

Evans, Vyvyan and Jörg Zinken

to appear Figurative language in a modern theory of meaning construction: A lexical concepts and cognitive models approach. In C. Makris and R. Christley (eds.), Art, Body and Embodiment. Cambridge: Cambridge Scholars Press.

Fauconnier, Gilles Available on-line at http://www.vyvevans.net.

1997 Mappings in Thought and Language. Cambridge: Cambridge University Press.

Fauconnier, Gilles and Mark Turner

2002 The Way We Think: Conceptual Blending and the Mind's Hidden Complexities. New York: Basic Books.

Fillmore, Charles

1982 Frame semantics. The Linguistic Society of Korea (ed.), Linguistics in the Morning Calm. Hanshin, 111-137.

1985 Frames and the semantics of understanding. Quaderni di Semantica 6, $222-254$.

Fillmore, Charles, and Beryl T. Atkins

1992 Toward a frame-based lexicon: The semantics of risk and its neighbors'. In Lehrer, A. and E. F. kittay (eds.), Frames, Fields and Contrasts. Hillsdale, NJ: Lawrence Erlbaum, 75-102.

Gentner, Dedre and Lera Boroditsky

2001 Individuation, relational relativity and early word learning'. In Bowerman M. and S. Levinson (eds.), Language Acquisition and Conceptual DevelopGibbs, Raymond W. ment. Cambridge: Cambridge University Press.

1994 The Poetics of Mind. Cambridge: Cambridge University Press.

Goffman, Erving

1981 Forms of Talk. Philadelphia: University of Pennsylvania Press.

Goldberg, Adele

1995 Constructions: A Construction Grammar Approach to Argument Structure. Chicago: Chicago University Press.

2006 Constructions at Work: The Nature of Generalization in Language. Oxford:

Grice, H. Paul Oxford University Press.

1975 Logic and conversation. In P. Cole and J. L. Morgan (eds.), Syntax and Semantics 3: Speech Acts. New York, NY.: Academic Press, 41-58.

Gries, Stefan Th.

2006 Corpus-based methods and cognitive semantics: The many meanings of to run. In Gries, Stefan Th. and Anatol Stefanowitsch (eds.), Corpora in Cognitive Linguistics. Corpus-Based Approaches to Syntax and Lexis. Berlin/New

Gumperz, John York: Mouton de Gruyter.

1982 Discourse Strategies. Cambridge: Cambridge University Press.

Haiman, John

1980 Dictionaries and encyclopedias. Lingua 50, 329-357.

Herskovits, Anette

$1986 \quad$ Language and Spatial Cognition. Cambridge: CUP. 
Kendon, Adam

2004 Gesture: Visible Action as Utterance. Cambridge: Cambridge University Press.

Lakoff, George

1987 Women, Fire and Dangerous Things: What Categories Reveal About the

Langacker, Ronald Mind. Chicago: University of Chicago Press.

1987 Foundations of Cognitive Grammar, vol. I. Stanford: Stanford University Press.

2000 A dynamic usage-based model. In M. Barlow and S. Kemmer (eds.), Usage-based Models of Language. Stanford, CA.: CSLI Publications, 164.

Michaelis, Laura

2003 Word meaning, sentence meaning, and syntactic meaning. In Cuyckens, H.,

R. Dirven and J. Taylor (eds.), Cognitive Approaches to Lexical Semantics. Berlin/New York: Mouton de Gruyter, 163-210.

Prinz, Jesse

2002 Furnishing the Mind: Concepts and their Perceptual Basis. Cambridge, MA: MIT Press.

Pustejovsky, James

1995 The Generative Lexicon. Cambridge, MA: MIT Press.

Searle, John

1969 Speech Acts: An Essay in the Philosophy of Language. Cambridge: Cam-

Schiffrin, Deborah bridge University Press.

1987 Discourse Markers. Cambridge: Cambridge University Press.

Schmid, Hans-Jörg

2000 English Abstract Nouns as Conceptual Shells: From Corpus to Cognition.

Sharifian, Farzad Berlin/New York: Mouton de Gruyter.

2003 On cultural conceptualisations. Journal of Cognition and Culture 3(3), 187-207.

Sinha, Chris

In print Cognitive linguistics, psychology and cognitive science. In Geeraerts, Dirk and Hubert Cuyckens (eds.), Handbook of Cognitive Linguistics. Oxford: Oxford University Press.

Sperber, Dan and Deirdre Wilson

1995 Relevance: Communication and Cognition, 2nd ed. Oxford: Blackwell.

Stefanowitsch, Anatol and Stefan Th. Gries

2003 Collostructions: Investigating the interaction between words and constructions. International Journal of Corpus Linguistics 8 (2), 209-243.

Sweetser, Eve

1999 Compositionality and blending: Semantic composition in a cognitively realistic framework. In Janssen T. and G. Redeker (eds.), Cognitive Linguistics: Foundations, Scope and Methodology. Berlin/New York: Mouton de

Talmy, Leonard Gruyter, 129-162.

1977 Rubber sheet cognition in language. Chicago Linguistics Society 13.

Tomasello, Michael

1999 The Cultural Origins of Human Cognition. Harvard: Harvard University Press. 
2003 Constructing a Language: A Usage-based Theory of Language Acquisition. Harvard: Harvard University Press.

Tyler, Andrea and Vyvyan Evans

2001 Reconsidering prepositional polysemy networks: The case of 'over'. Language 77(4), 724-765.

2003 The Semantics of English Prepositions: Spatial Scenes, Embodied Meaning and Cognition. Cambridge: Cambridge University Press.

Złatev, Jordan

1997 Situated Embodiment: Studies in the Emergence of Spatial Meaning. Stockholm: Gotab.

2003 Polysemy or generality? Mu. In Cuyckens H., R. Dirven and J. Taylor (eds.), Cognitive Approaches to Lexical Semantics. Berlin/New York: Mouton de Gruyter, 447-494.

Zwaan, Rolf

2004 The immersed experiencer: Toward an embodied theory of language comprehension. In Ross, B. H. (ed.), The Psychology of Learning and Motivation, vol. 44. New York: Academic Press, 35-62. 